\title{
The Glasgow Miracle Project: working with an arts organisation's archives
}

\section{Susannah Waters, Glasgow School of Art}

\section{Introduction}

The term The Glasgow Miracle is believed to have first been used in the mid-1990s by the Swiss curator Hans Ulrich Obrist in reference to the emergence of a strong artistic community in the city at this time. This decade also saw the artist Douglas Gordon become the first Glasgow-based winner of The Turner Prize (a significant contemporary art prize in the UK). The ongoing success of Glasgow-trained or Glasgow-based artists in relation to this prize has helped to establish the city's reputation as an arts centre of international importance. Since Gordon won the award in 1996, an additional 16 Turner Prize nominees and five winners have been linked to the city. Glasgow is now a place where artists come to train, live and work, and are able to stay and sustain their practice.

Although the transformation of this post-industrial area into a successful hub for the visual arts may seem to have been a miraculous occurrence, those within the artistic community understand that the city has undergone a more gradual, accumulative, and sustainable change, based on a range of artistic activities and strategic funding policies. ${ }^{1}$ In order to explore these developments more closely, The Glasgow School of Art (GSA), in partnership with the CCA: Centre for Contemporary Arts, undertook an 18 month AHRC funded research project entitled: The Glasgow Miracle: Materials for Alternative Histories. This project worked with a number of previously unorganised and therefore fairly inaccessible archive collections, dating from the 1970s to 2000s, a period of significant change and growth for the contemporary arts in Glasgow. These archives included:

- The archives of the Third Eye Centre and the Centre for Contemporary Art (CCA); Glasgow's two main contemporary arts venues of the period, The Third Eye being generally seen as the direct predecessor to the CCA

- The George \& Cordelia Oliver Collection: a personal archive of an important art critic, commentator and collector, acquired by the Glasgow School of Art in 2008

- A set of video recordings, in VHS format, that were made during the staging of events at the Third Eye Centre

The project also created a new set of artists' interviews between Ross Sinclair (a Glasgowbased artist and researcher on the project) and a number of artists who have played significant roles and have contributed to the contemporary art movement in Glasgow. 
The project team comprised of:

- Principal Investigator: Dr Francis McKee (Director of the CCA and Lecturer at GSA)

- Co-investigator: Ross Sinclair (Artist and Lecturer at GSA)

- Project Coordinator and Research Assistant: Carrie Skinner (GSA)

- Archivist: Susannah Waters (GSA)

- External Advisor: Dr Dominic Paterson (Glasgow University)

- Research Advisor: Julie Ramage (GSA)

\section{Working with the archives}

As the archive material used in this project was uncatalogued, it had not previously been heavily used by researchers. However, the project team recognised that it had the potential to provide valuable information about the artistic activities which were happening in Glasgow during the late twentieth and early twenty-first centuries - information on how and why these activities were developed, and information on how they were received by their audiences. The team also wished to encourage further research into this area, and it was therefore felt essential to catalogue the archive materials as part of the research process, and to ensure that any actions undertaken would support the longer-term preservation and accessibility of the records. The George \& Cordelia Oliver Archive was housed at Glasgow School of Art's Archives and Collections Centre, an established archive repository, with in-house expertise and facilities, ensuring a stable, long-term future for the material. However, the future of The Third Eye and CCA archives was less certain. The Third Eye archives had been deposited with Glasgow City Archives when the organisation went into administration in 1990-1991 but the material was returned to the custodianship of the CCA for the purposes of The Glasgow Miracle Project. ${ }^{2}$ The project team were keen for the material to be housed and managed by the CCA as this was the organisation which had originally created it, and it was felt that this would ensure the archives would be actively used to support the sorts of activities (exhibitions and events) which its records documented. However, it was acknowledged that there were a number of associated risks with this arrangement as, at that time, the CCA did not have any established archive facilities or staff dedicated to this area. The team therefore set about creating a cataloguing system and repackaging programme which could be sustained by the CCA in the future if this proved desirable. They also began to explore how the CCA's facilities could be devel- 
oped in line with best practice guidelines. This process involved discussions with a wide variety of stake holders, including archivists, curators, artists and researchers. The team also met with other visual arts organisations in Glasgow and the wider UK who had experience of working with in-house archives, ${ }^{3}$ and they consulted online information from bodies such as: The National Archives, The Community Archives and Heritage Group, ICON and The National Register of Archives for Scotland.

\section{Arrangement and cataloguing}

The cataloguing and repackaging programme for The Third Eye and CCA archives was also informed by the volume, medium and arrangement of the material itself. These activities came under the remit of the Project Coordinator and Research Assistant with advice provided by a professional archivist, the author. On assessing the volume of material in question, it was felt that in order to create a suitably detailed catalogue, additional support would be required. Five volunteers were therefore recruited to assist with listing and repackaging. These volunteers were able to test out the cataloguing, digitisation, and repackaging processes that had been developed by the Project Coordinator and Research Assistant in collaboration with the Archivist. It was important to ensure that these processes could be followed consistently by individuals who did not have a specialised knowledge of archival theory as it was recognised that in the future, if the material was held at the CCA, it was unlikely due to budget restrictions, that they would be able to recruit a professionally qualified archivist to undertake this work. ${ }^{4}$

After investigating a number of options, the project team decided to use excel software to catalogue The Third Eye and CCA archives. The team wanted to use software that was familiar to a wide range of users and which was easy to access and inexpensive. Excel was chosen over a word-processing package, such as Word, so that the data could be sorted into fields and, so that future importing and exporting of data could be facilitated if necessary. Open source archive catalogues such as Atom and $\operatorname{Archon}^{5}$ were also considered, however it was felt that the knowledge of archival terminology and the IT support required could prove problematic when trying to sustain this work in the future. Instead, a spreadsheet was set up with columns that reflected the key $\operatorname{ISAD}(G)$ fields: reference number, title, date and creator, and guidelines were created, outlining how each of these fields should be completed. It should be noted that, at this point, a field for level wasn't included as the arrangement of the material had not been fully agreed upon. This spread- 
sheet has since been used to disseminate the archive catalogues online via the project website: http:// www. glasgow miraclearchives.org/ archive-catalogue/

The original order of The Third Eye and CCA archives were distinctly different, reflecting the different management structures and modes of operation of each organisation. The Third Eye archive consisted of just over 100 boxes of paper based records including correspondence, financial documents, project paperwork and publicity materials (see Figure 1). This material was grouped loosely by date; however it did not fall into any clear areas which would suggest an organisational structure or division of functions. From the team's research into The Third Eye's activities, it seems that the individuals who worked for this organisation often multi-tasked and took on a number of roles. There were therefore few distinctions between one department or function, and the seeming dis-order of the surviving paperwork was potentially a result of this mode of working. With this in mind, it was agreed that the paperwork should not be rearranged (a probably impossible task), but that each file should be name and subject indexed, so that future users could more easily navigate their way around the material. UKAD's indexing tutorial ${ }^{6}$ was referred to in order to develop an appropriate level of indexing for the collection, and index terms were, in the main, based on the Getty Art and Architecture Thesaurus, ${ }^{7}$ although in some cases it was necessary to add our own specialised terms. As the cataloguing process progressed, a fairly strict list of subject index terms was developed by the Project Coordinator and Research Assistant. Volunteers would note if they came across any material that didn't fit into an existing subject term and a new term would be added if necessary. Using excel supported this ongoing development of index terms, as updating an existing term could be quickly undertaken using the 'find and replace' function. Research use of the material has tested out these index terms and proved their usefulness. It has also shown that, in general, the researchers that have used the collection have enjoyed the slightly disorganised nature of its arrangement, feeling that it still retains a sense of the original use of the records.

In contrast to The Third Eye's records, the material in the CCA archive reflected a more structured organisation and was generally grouped according to the department that had created it, for example exhibitions programming materials, education activity materials, publicity, financial documents etc. This resulted in a more hierarchical catalogue, which was structured to reflect the functional areas of the existing materials, and to allow for additional items to be easily added. This structure was developed by the Project Coordinator and Research Assistant with input from the Archivist. Volunteers worked on one section at a time (each section being listed on a separate excel sheet). 
As a result of our project, the Project Coordinator and Research Assistant, and the Archivist have been approached by a number of other arts organisations asking for advice on how to start archiving their records. We have observed that although the need to catalogue their material using a standardised format is generally already understood by the individuals involved, the hierarchical nature of archive catalogues is an area which is generally unfamiliar to non-archivists. One resource we have found particularly useful in helping explain this, are the cataloguing guidelines produced by the Community Archives and Heritage group. ${ }^{8}$ We have also noted that a number of arts organisations who are already archiving, or who are about to start this work, were not aware of organisations that could offer advice or support in this area. Hopefully this will change as initiatives such as The National Archives Archiving the Arts become more established. ${ }^{9}$ If a network of organisations who support archiving arts-related records can flourish, it will ensure material held by individual artists and arts organisations is made accessible to future generations. Although most of the organisations the author has spoken to did not seem to wish to donate their material to an established archive, (feeling this would potentially make it less accessible to them), they were interested in working more closely with the archive profession if this option were available. The current interest and enthusiasm within the fine arts sector for archiving should be harnessed while the opportunity is there. For the archive sector, it opens up their work to a new user group and provides a wide range of potential advocacy activities such as exhibitions, events and talks. ${ }^{10}$ If the profession can also help to 'train' organisations to look after their own material, it could potentially lessen space and resource pressure on local archive repositories whilst still ensuring documentary evidence about the activities of their locality survive and are made accessible to researchers.

\section{Motivations}

In recent years the use of archives, or references to archiving processes, have become increasingly common in the work of visual artists. Well known practitioners such as Gerard Byrne, Kate Davis, Elizabeth Price and J amie Shovlin, to name a few, have all created work relating to archives. Such an interest is also evident when talking to arts organisations who are keen to explore their history and document their current activities. The research focus of The Glasgow Miracle Project reflected a growing interest in examining the development and success of the fine arts in Glasgow, not just from academics but also from artists and galleries based in the city. Many of these organisations have their roots in the 1970s and 1980s, a period still within living memory, but sufficiently long ago to feel historical; they are at a point in their development in which they have been established 
long enough to be able to reflect on their own history. The CCA opened in C. 1991 and is therefore not a particularly old organisation. However, enough time has passed to create an aura of history around its early records, and the records of its predecessor body, The Third Eye Centre (established 1973). Most current personnel know about the recent activities of the organisation, but material from twenty, or even ten years ago contains unfamiliar information. The format of many of the records is also sufficiently unfamiliar to stimulate curiosity - typewritten documents, VHS and audio tapes already being a thing of the past.

It's interesting to note that the CCA had kept a substantial amount of its records, even though it had not heavily used them prior to The Glasgow Miracle Project. It seems the usefulness of archives (to support current activities and to inform future planning) was recognised by the organisation's staff but a specific impetus, such as the research project, was needed to start actively opening up their full potential. The availability of funding was of course a key factor that allowed archiving work to be undertaken. ${ }^{11}$ However, as with all archives, the organisation needed to evaluate their ongoing usefulness in order to justify setting aside long-term resources to manage and develop them after the project had been completed. As will be seen below, the archives have already supported a number of activities and plans are in place for further initiatives.

\section{Uses}

The Glasgow Miracle Project proposed that arts organisations' archives were an essential tool in researching the cultural regeneration of Glasgow. The growing interest in accessing these archives has since confirmed that this material can also be used for a wide variety of other purposes. During the project, access to the archives wasn't actively advertised; however since 2012 the team has still been able to provide access to almost 100 researchers which have included artists, curators, academic researchers, staff from GSA and the CCA, and the media. Researchers were interested in a number of different areas, including researching particular artists and/ or exhibitions, exploring the development of video art in Glasgow, community arts projects, and the general working of The Third Eye Centre i.e. 'how to set up an arts centre in a post-industrial city'. Facilitating such access allowed us to test out our cataloguing system and to explore how the archives might be used once fully catalogued and more accessible. With this in mind, the project team also organised an exhibition to coincide with the mid-point of the project. 
This exhibition, "What We Have Done, What We Are About To Do", was held at the CCA between 18 August and 15 September 2012. It allowed the team to explore how the archives could be used by their creating organisation to support its key activities of exhibition planning and public engagement, (in particular engaging with local communities and practicing artists). The title of the exhibition was taken from an early Third Eye publication which talks about the opening of the Centre in its Sauchiehall Street premises in 1975. The timing of this show was deliberately chosen to take place during the project as opposed to after it had been completed in order to provide an insight into what the project was doing, and to encourage others who had an interest in this period to become involved. As expected, many of the visitors had existing links to The Third Eye or to the CCA. However, others had little knowledge of the history of these organisations and wished to gain a deeper understanding about them and Glasgow's artistic heritage. The exhibition allowed the project to show materials to a much larger number of people than could be facilitated through archive visits alone. It certainly raised awareness of the project, and it helped the team to explore how the material could be utilised. It confirmed current artistic practitioners and the general public were interested in this subject matter and in accessing and using archives more generally.

The exhibition's display consisted of three rooms: one holding a selection of paper archive items, illustrating what sort of material was held in the archives; one showing videos of events at the Third Eye in the 1970s; and one showing a number of new pieces created by different individuals including writers, curators, artists and musicians (see Figure 2, Figure 3 and Figure 4). The archive materials and videos prompted much reminiscing from many of the visitors. In several cases, this lead to more formal interviews being undertaken with the project's researchers, which aided their understanding of the archive material and the subject area they were interested in. The exhibition and the project team's interaction with its visitors also helped to give the project greater relevance to the local community and not just to the researchers' academic peers. Moreover, the process of commissioning contemporary art works allowed a new generation of practitioners to discover this period of the city's history and in some cases, to work with archives for the first time. The CCA asked two Glasgow-based artists Rebecca Wilcox and Oliver Pitt to undertake the commissioning process, they in turn approached other creative practitioners with the remit that they should respond to the project as they wanted to, or respond more generally to the concept of the archival process, its 'relevance and authority'. The newly created exhibits changed throughout the exhibition, allowing for a greater number of pieces to be included and also emphasising the wide variety of responses this material and the project had solicited. About 15 contributors took part in total, the variety of responses 
on display confirming the rich potential of the archives as a continued resource for creative inspiration. ${ }^{12}$ Since this show, another exhibition has been held at the CCA which has also utilised the archives. Speaking in Tongues (8 February - 23 March 2014), showed the work of three artists: Sonia Boyce, Pavel Büchler, and Susan Hiller, who had all previously exhibited at The Third Eye Centre in the 1980s. Although this exhibition didn't include original material from the archives, the decision to bring these three artists' work together was developed from looking through the archival records. ${ }^{13}$

During the project, the archives and the subject of archiving and artistic practice were also explored through a number of public talks, including events delivered at the CCA, a conference co-organised with ARLIS (The Art Libraries Society), and held at the White Cube Gallery in London ${ }^{14}$, and talks given at events organised by the Scottish Records Association ${ }^{15}$ and the Business Archives Council of Scotland. These events brought together archivists and creative practitioners to explore links between archives and artists, and to discuss how archives can be managed and utilised by arts organisations, artists, researchers and curators. The project team had many useful conversations as a result of these events which informed our activities. They certainly made the team realise how many people are interested in arts archives and the use of archives in creative practice in the UK, and what potential there is for closer links between these individuals.

The above activities helped the team to disseminate their work to others, to gain new knowledge about the project's subject matter, and to consider different approaches to working with archives. They also proved that the archives of an arts organisation are relevant and useful to its current activities of exhibiting and public engagement. In addition to the events organised as part of the project, the archives have also been used to support the development of public tours at GSA and the CCA, (GSA runs a city walking tour linked to the 'Glasgow Miracle', ${ }^{16}$ and the CCA delivers a tour which explores its history); to enhance the event archive on the CCA's website; ${ }^{17}$ and to supply images for use on TV and in the press. This is important, as it can be argued that a more public profile and clearly documented history helps to maintain the future security of an organisation something which is particularly relevant for arts activities which often require external funding. On a less public scale, The Third Eye and the CCA archives have also been used by current CCA staff to find out more about the history of their own organisation. It is hoped that continued use of the archives will promote a greater sense of community and identity amongst the staff, and also assist with forward planning: giving practical information about how events have previously been organised and providing inspiration for new ideas. 


\section{Future developments}

Since the beginning of our project, the CCA have developed an archive room to house their collections and provide user access. They have also reviewed their current and semi-current records with a view to maintaining a sustainable archiving process. The project team believe that the archive will continue to be used by the CCA to support its own activities and they wish to continue to encourage more external researchers to access these records. With this in mind, a project website has been developed ${ }^{18}$ (Figure 5) which provides online catalogue access, and the project team are working with GSA colleagues to develop the use of the archives as a teaching, learning and research resource where appropriate. Ongoing maintenance of the archive will be a significant undertaking, requiring resources and in-house expertise. However, the author believes that the CCA will be well-supported by the archive community in Glasgow and this should help ensure they are able to assess how best to focus their resources and energy in relation to their archiving activities. The project team plan to continue to research the development of arts centres and it is predicted that in doing so we will come across more archival material held in private hands. It will be interesting to ascertain if the owners of this material wish to donate it to a public archive or, like the CCA, are looking for assistance in archiving their own materials. As noted previously in this article, the project team has already been asked for advice by other arts organisations in Scotland who wish to start archiving their records. We have been happy to discuss our experiences with these groups but we have also been keen to point them in the direction of professional bodies who can offer up-to-date, best practice advice on archiving and conservation activities. The arts organisations we have spoken to have all wished to keep their archives in-house in order to fully utilise their potential. However, like the CCA they have limited resources to commit to this area of activity and require support and advice from archive professionals. It seems that a model of arts organisations managing their own archives with support from the archive profession may be emerging.

\section{Conclusion}

The Glasgow Miracle Proj ect's research activities and subject area necessitated using archive collections relating to The Third Eye Centre and the CCA which the team realised required cataloguing work in order to make them suitably accessible. Although a professionally trained archivist would ideally have undertaken these activities, the resources on hand meant that this wasn't feasible. Instead, an Archivist and a Project Coor- 
dinator and Research Assistant with experience of working with archives, developed cataloguing and preservation guidelines which aimed to implement best practice archive processes in a way that was accessible to individuals without professional archival training and with limited resources. An excel spreadsheet, structured to reflect ISAD(G)'s key fields was used, and a set of subject index terms developed based on the Getty Art and Architecture Thesaurus. Project team members and volunteers brought knowledge of the archive's subject matter which greatly assisted in identifying and describing the materials. Their current involvement in contemporary arts activities in Glasgow also ensured that the material was used to support the types of activities (exhibition and educational events) which it originally related to.

The archives have already been used to develop two exhibitions, and as the basis of a number of talks and events. They have also helped raise the profile of GSA and the CCA through the development of public tours based on Glasgow's artistic heritage, the creation of new website information for the CCA, and their use by the media for TV and press. Awareness of the archives within the project team's organisations (CCA and GSA) also continues to increase and it is envisioned they will continue to support their key activities (teaching, learning and research at GSA, and exhibitions and public engagement at the (CA). It is clear from these activities that the archives will be accessible and well used if they are kept at the CCA. This organisation is therefore now working with Glasgow City Archives to ensure their new archive facilities and processes will support the long-term security and preservation of The Third Eye archives. It is hoped a collaborative model can be developed which could potentially be implemented between other arts organisations and local archive repositories. The experience of The Glasgow Miracle Project team is that an increasing number of arts organisations wish to actively work with their archives but are currently unaware of where to look for advice. It is hoped that disseminating information about this project's experiences will help to connect more of these organisations with other working in this area, from the archive profession and from the contemporary arts community. 


\section{Figure Captions}

Figure 1: The Third Eye archive before cataloguing and repackaging work had started. Image: Carrie Skinner, 2012.

Figure 2: Items from The Third Eye archive on display at "What We Have Done, What We Are About To Do" exhibition at the CCA, 18 August - 15 September 2012. Image: CCA, 2012.

Figure 3: Video recordings of events at The Third Eye Centre on display at "What We Have Done, What We Are About To Do" exhibition at the CCA, 18 August - 15 September 2012. Image: CCA, 2012.

Figure 4: Contemporary work created in response to The Glasgow Miracle: Materials for Alternative Histories project on display at "What We Have Done, What We Are About To Do" exhibition at the CCA, 18 August - 15 September 2012. Image: CCA, 2012.

Figure 5: The Glasgow Miracle: Materials for Alternative Histories project website: www. glasgowmiraclearchives. org 2014

\section{Endnotes}

1. http:// glasgowmiracle.blogspot.co.uk/p/about-project.html accessed 04 August 2014

2. The project team has continued to work closely with Glasgow City Archives to ensure the ongoing security, preservation and access of these records.

3. The author would like to thank all of the organisations who spoke to her about their work for their time and enthusiasm, namely: The Glasgow Print Studio; IKON Gallery, Birmingham; The Modern Institute, Glasgow; Street Level Photoworks Glasgow; Transmission Gallery, Glasgow; Whitechapel Gallery, London; Woodend Barn, Banchory. Speaking to these organisations highlighted the growing interest in art-related archives across the UK, (all of these organisations had only started their work in the last 10-15 years).

4. The volunteers also played a key role in helping to disseminate information about the project via the project blog and via word of mouth.

5. https:// www.ica-atom.org and http:// www. archon.org

6. http:// www. ukad. org/ UKAD-Indexing-Tutorial/ index. html 
7. http:// www. getty. edu/ research/tools/ vocabularies/ aat/

8. http:// www. communityarchives. org. uk/ content/ resource/ cataloguing guidelines

9. http:// www. nationalarchives. gov.uk/ archives-sector/ archiving-the-arts. htm

10. Examples of working with artists and designers to exhibit archive materials can be found in the following article: Magee, Karl and Waters, Susannah "Archives, Artists and Designers" J ournal of the Society of Archivists Volume 32, Issue 2, (2011): 273-285.

11. The availability of funding, and a renewed interest in the history of an organisation (often linked to a landmark anniversary) were common factors across a number of the other arts organisations the author has spoken to.

12. Work was produced for the exhibition in a variety of formats including print, video and audio. Some artists commented on the concept of the archive in general, others focused on specific events from the history of The Third Eye and CCA, and some took items from the archive and repurposed them to become part of a new work.

13. http:// cca-glasgow.com/ programme/ 529e05aba4e1b4f325000313

14. https:// gsaarchivesandcollections. wordpress.com/2013/ 06/ 10/ final-programme-for-giving-upthe-archive-study-day-announced/

15. http:// www. scottishrecordsassociation. org/ index. php/ news-archive/ 11-newsevents/ archive/ 80-et-in-archiva-ego-artists-in-the-archives-and-thirty-sixth-annual-generalmeeting-of-the-sra

16. http:// www.gsa.ac.uk/ visit-gsa/ city-walking-tours/ explore-the-glasgow-miracle/

17. http:// cca-glasgow.com/archive

18. http:// www. glasgowmiraclearchives. org 